\title{
Chlorine NQR on Derivatives of Chloral
}

\begin{abstract}
Masao Hashimoto, Norbert Weiden, and Alarich Weiss
Institut für Physikalische Chemie, Physikalische Chemie III,

Technische Hochschule Darmstadt

Z. Naturforsch. 35a, 1045-1053 (1980); received July 28, 1980

The ${ }^{35} \mathrm{Cl}-\mathrm{NQR}$ spectrum of several derivatives of chloral, $\mathrm{Cl}_{3} \mathrm{CCHO}$, was studied in the range $77 \mathrm{~K} \leqq T \leqq T_{\mathrm{m}}$. By use of the spin echo double resonance technique a relative assignment of the resonances to different $\mathrm{Cl}_{3} \mathrm{C}$-groups within one crystallized compound was possible. The solid compounds studied are: High temperature phase of chloral hydrate, $\mathrm{Cl}_{3} \mathrm{CCH}(\mathrm{OH})_{2}$; parachloral, $\left(\mathrm{Cl}_{3} \mathrm{CCHO}\right)_{3},(\alpha$ - and $\beta$-isomer $)$; the two phases of chloral hemihydrate $\mathrm{Cl}_{3} \mathrm{CCHO} \cdot 1 / 2 \mathrm{H}_{2} \mathrm{O}$; chloralide (II); chloralhemithiohydrate, $\mathrm{Cl}_{3} \mathrm{CCHO} \cdot 1 / 2 \mathrm{H}_{2} \mathrm{~S}$. The structure of the molecules in the solid state and the fade out of the NQR resonances are discussed.
\end{abstract}

\section{Introduction}

A simple compound carring a trichloromethyl group, $\mathrm{CCl}_{3}$, is trichloroacetaldehyde (chloral), $\mathrm{CCl}_{3} \mathrm{CHO}$. It was prepared for the first time and extensively studied by Liebig [1]. The chemistry of chloral was recently reviewed by Luknitskii [2]. In course of studies of chloral hydrate, $\mathrm{CCl}_{3} \mathrm{CH}(\mathrm{OH})_{2}$ $[3,4]$ and of several trichloromethyl derivatives [5, 6] the relative intramolecular configuration of different $\mathrm{CCl}_{3}$ groups within one molecule or within one crystallographically asymmetric unit was of interest. It has been shown that Spin Echo Double Resonance, SEDOR [7], offers an experimental way to contribute to the problem [8,9]. Here SEDOR is applied besides wide line Nuclear Quadrupole Resonance (NQR) for the study of the relative configuration of the following compounds: high temperature phase of chloral hydrate, $\mathrm{CCl}_{3} \mathrm{CH}(\mathrm{OH})_{2}(\mathrm{I})$, the two solid phases (I) and (II) of chloral hemihydrate, $\mathrm{CCl}_{3} \mathrm{CHO} \cdot 1 / 2 \mathrm{H}_{2} \mathrm{O}$, the ester chloralide, $\mathrm{CCl}_{3} \mathrm{CHOCOCHOCCl}_{3}$ (which shows a solid state

phase transformation above room temperature), the two isomers of trimeric chloral, $\left(\mathrm{CCl}_{3} \mathrm{CHO}\right)_{3}$, known as $\alpha$-parachloral and $\beta$-parachloral, and chloral hemithiohydrate, $\mathrm{CCl}_{3} \mathrm{CHO} \cdot 1 / 2 \mathrm{H}_{2} \mathrm{~S}$.

The application of NQR is of particular advantage in the study of solid trichloromethyl derivatives where in numerous examples solid state transformations have been observed. By means of $\mathrm{Cl}-\mathrm{NQR}$ it is possible to follow up the transformation process

Reprint requests to Prof. Dr. A. Weiss, Institut für Physikalische Chemie, Technische Hochschule Darmstadt, Petersenstraße 20, D-6100 Darmstadt. and the onset of hindered rotation of the $\mathrm{CCl}_{3}$ groups which results in a "fade-out" of the NQR lines.

\section{Experimental}

\section{Preparation of the Compounds}

The high temperature phase of chloral hydrate, $\mathrm{CCl}_{3} \mathrm{CH}(\mathrm{OH})_{2}(\mathrm{I})$, and trichloroethylidene trichlorolactic ester (chloralide), $\mathrm{CCl}_{3} \mathrm{CHOCOCHOCCl}_{3}$, were obtained as described previously $[3,4,6]$. Chloral hemithiohydrate, $\mathrm{CCl}_{3} \mathrm{CHO} \cdot 1 / 2 \mathrm{H}_{2} \mathrm{~S}$, was synthesized from chloral hydrate and $\mathrm{H}_{2} \mathrm{~S}$ according to Chattaway and Kellett [10]. $\alpha$-parachloral and $\beta$-parachloral, $\left(\mathrm{CCl}_{3} \mathrm{CHO}\right)_{3}$, were prepared from chloral hydrate and sulphuric acid by the method given by Chattaway and Kellett [11]. Chloral hemihydrate, $\mathrm{CCl}_{3} \mathrm{CHO} \cdot 1 / 2 \mathrm{H}_{2} \mathrm{O}$, was synthesized from $\mathrm{CCl}_{3} \mathrm{CHO}$ and $\mathrm{CCl}_{3} \mathrm{CH}(\mathrm{OH})_{2}$ in the following way: One mole of $\mathrm{CCl}_{3} \mathrm{CH}(\mathrm{OH})_{2}$ (solid) was mixed with one mole of $\mathrm{CCl}_{3} \mathrm{CHO}$ (liquid). The mixture was warmed up to ca. $330 \mathrm{~K}$ to dissolve the solid part thoroughly. To the liquid thereafter a trace of sulphuric acid was added and by annealing at ca. $295 \mathrm{~K}$ the liquid solidified completely within one hour. The compound can be recrystallized from $\mathrm{HCCl}_{3}$. The results of chemical analysis are (calc/ found) : $\mathrm{C}(15.360 \% / 15.10 \%) ; \mathrm{H}(1.289 \% / 1.15 \%)$. The existence of chloral hemihydrate has been proposed by van Rossen [12] and Shill [13]. Immediately after solidification $\mathrm{Cl}_{3} \mathrm{CCHO} \cdot 1 / 2 \mathrm{H}_{2} \mathrm{O}$ showed at $77 \mathrm{~K}$ a very weak, six line ${ }^{35} \mathrm{Cl}-\mathrm{NQR}$ spectrum. Within a few days the signals became relatively strong. The same spectrum was observed

0340-4811 / $80 / 1000-1045 \$ 01.00 / 0$. - Please order a reprint rather than making your own copy. 
for a specimen recrystallized from $\mathrm{HCCl}_{3}$. The polycrystalline substance obtained in that way was sealed in a glass ampoule and kept at room temperature. Within several weeks a different set of ${ }^{35} \mathrm{Cl}$ NQR signals appeared for this sample. The new signals became more intense day by day at the expense of the six line spectrum and after three months a new spectrum consisting of twelve ${ }^{35} \mathrm{Cl}-\mathrm{NQR}$ lines of fairly good signal to noise ratio was observed. These two crystalline phases are designated as phase I (six lines) and phase II (twelve lines), respectively. The IR spectrum of the compound (KBr-disk) shows the presence of an ether bond, suggesting the following structure:<smiles>OC(OC(C(Cl)(Cl)Cl)C(Cl)(Cl)Cl)C(Cl)(Cl)Cl</smiles>

\section{NQR Spectroscopy}

The search for the ${ }^{35} \mathrm{Cl}-\mathrm{NQR}$ lines was done with a superregenerative Zeeman modulated spectrometer (Decca). For the SEDOR experiments a two channel pulse spectrometer [9] was employed. The temperature measurements (thermocouple at the sample) are accurate to $\pm 1 \mathrm{~K}$, the error in the frequency measurements is $\pm 3 \mathrm{kHz}$ and only due to the line width. Theory and experiment of SEDOR have been developed by Emshwiller, Hahn, and Kaplan [7]. For a SEDOR experiment the sample must contain at least two crystallographically inequivalent nuclei with spin $I \geqq 1$, which we call Aand B-nuclei. During the experiment the echo amplitude of the A-nuclei is monitored by a $90^{\circ}-\tau-180^{\circ}$ pulse sequence. At the time $\tau$ a third pulse with length $n \cdot 180^{\circ}$ is applied to the sample and the frequency of this rf-pulse is varied in steps while the whole pulse program is repeated. If the frequency of the third pulse matches one of the resonance frequencies of the B-nuclei, that part of the local magnetic field at the site of the A-nuclei which originates from the magnetic moments of the B-nuclei, changes its sign:

$$
h_{\mathrm{AB}} \rightarrow-h_{\mathrm{AB}} ; \quad h_{\mathrm{AB}}=\mu_{\mathrm{B}} / r_{\mathrm{AB}}^{3} .
$$

This leads to a disturbance of the phase memory of the A-spins, and consequently the echo amplitude of the A-nuclei is lowered. Following Emshwiller et al. the decrease of the A-echo amplitude $\Delta E$ can be formulated as

$\Delta E=\frac{1}{3} \gamma_{\mathrm{A}}^{2} \gamma_{\mathrm{B}}^{2} T_{\mathrm{AA}} I_{\mathrm{B}}\left(I_{\mathrm{B}}+1\right) \tau^{2} \hbar^{2} \sum_{k} g_{j k} r_{j k}^{-6}$.

$\gamma_{\mathrm{A}}, \gamma_{\mathrm{B}}$ are the gyromagnetic ratios of the A- and Bspins; $T_{\mathrm{AA}}$ is the relaxation time of the A-spins due to A-A interaction only, $I_{\mathrm{B}}$ the spin quantum number of the B-system, $\boldsymbol{g}_{j k}$ a geometrical factor and $\boldsymbol{r}_{j k}$ the distance between the nuclei $\mathrm{A}_{j}$ and $\mathrm{B}_{k}$.

In our experiments the width of the $90^{\circ}$ pulse for the A-spin system was $15 \mu \mathrm{sec}$ in all cases. The time intervall $\tau$ in the sequence $90^{\circ}-\tau-180^{\circ}$ was around $1000 \mu \mathrm{sec}$ at $77 \mathrm{~K}$ and $600 \mu \mathrm{sec}$ for measurements close to room temperature. For the length of the $n \cdot 180^{\circ}$ pulse applied to the B-system $400 \mu$ sec were choosen in order to avoid broadening of the B-spin resonance line through Fourier components of the B-pulse.

By heteronuclear double resonance it is possible to detect very weak NQR signals of the B-spin system via their influence on the A-signal, and the $1 / r^{6}$ dependence offers a way to determine relative distances between A and B nuclei. For this purpose heteronuclear [7], homonuclear [9] and isotopic double resonance can be used. The last two techniques have been applied to study the relative intramolecular configuration of chlorine nuclei in trichloroacetic acid and other compounds [9] and homonuclear double resonance was applied in this work, too.

\section{Results}

In Fig. $1-5$ the ${ }^{35} \mathrm{Cl}-\mathrm{NQR}$ frequencies are shown as a function of temperature. A normal Bayer type behaviour [14] is found for all five compounds, and in Table 1 the coefficients of the polynominals

$$
\nu(T)=A+B / T+C T+D T^{2}
$$

are given. This function describes the temperature dependence of $\nu\left({ }^{35} \mathrm{Cl}\right)$ in the range $77 \mathrm{~K} \leqq T \leqq T_{\mathrm{m}}$ ( $T_{\mathrm{m}}=$ melting point) adequately within the limits of experimental error in $v$ and $T$.

Table 2 lists the resonance frequencies $v\left({ }^{35} \mathrm{Cl}\right)$ of the compounds measured at $77 \mathrm{~K}$, together with $T_{\mathrm{m}}$ and the "fade-out" temperatures $T_{f}$. The fade-out temperature is defined as that temperature at which the ${ }^{35} \mathrm{Cl}-\mathrm{NQR}$ signals disappear in the noise (see [6]). Some of the signals fade out at temperatures far below the respective melting point, while others could be observed till the compound melted. No 


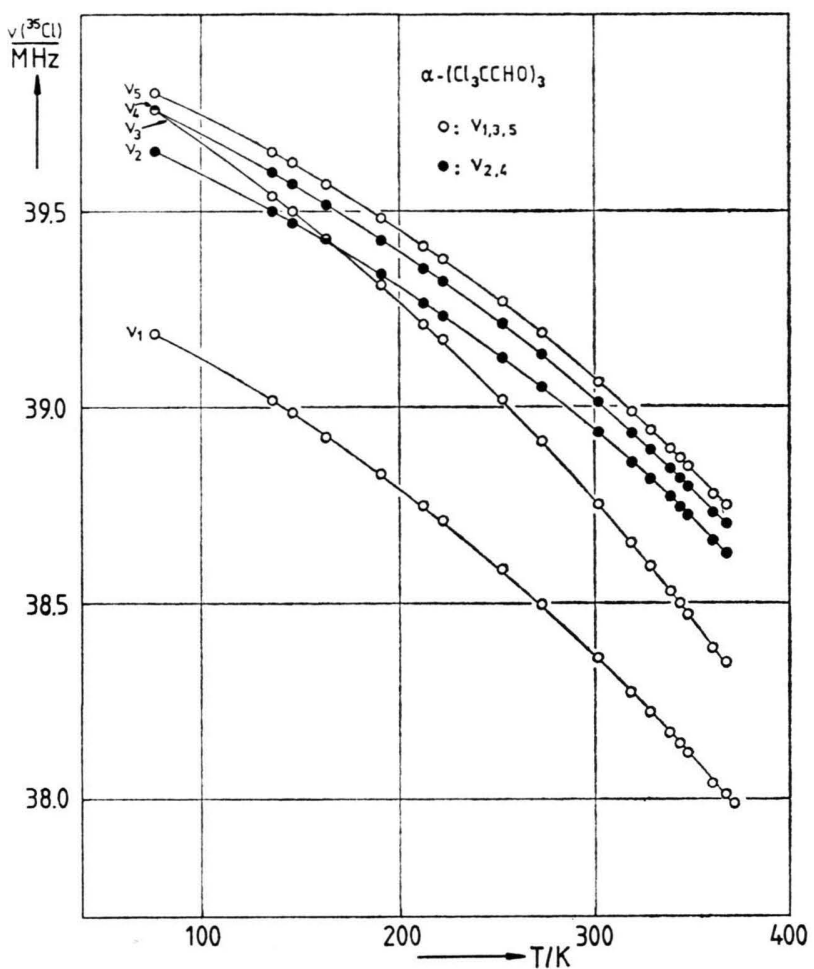

Fig. 1. Temperature dependence of the ${ }^{35} \mathrm{Cl}-\mathrm{NQR}$ frequencies in $\alpha$-parachloral, $\alpha$ - $\left(\mathrm{Cl}_{3} \mathrm{CCHO}\right)_{3}$.

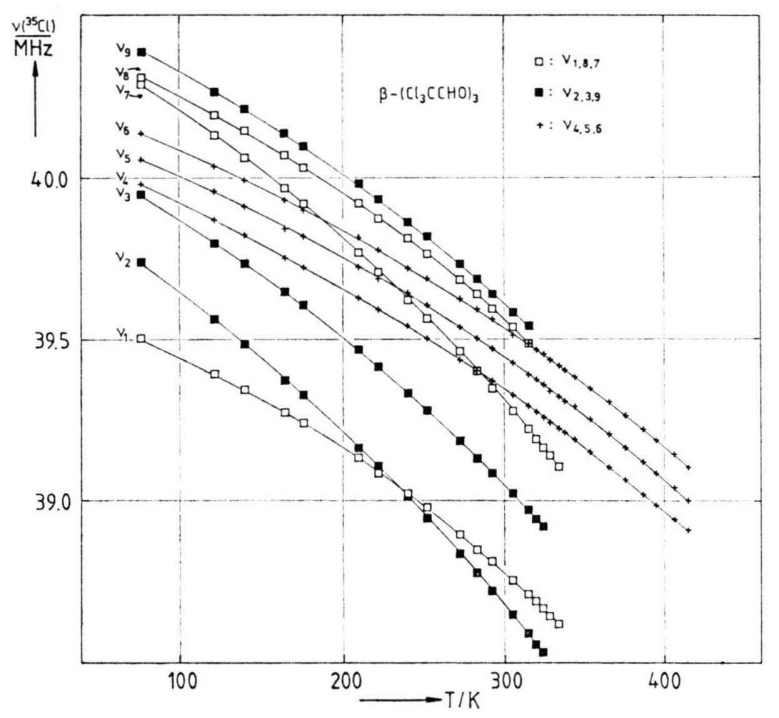

Fig. 2. Temperature dependence of the ${ }^{35} \mathrm{Cl}-\mathrm{NQR}$ frequencies in $\beta$-parachloral, $\beta$ - $\left(\mathrm{Cl}_{3} \mathrm{CCHO}\right)_{3}$.

anomaly was found in the $v\left({ }^{35} \mathrm{Cl}\right)=f(T)$ curves except for chloralide, which compound shows a reversible phase transformation, chloralide $(\mathrm{I}) \rightleftharpoons$ chloralide (II) [6].

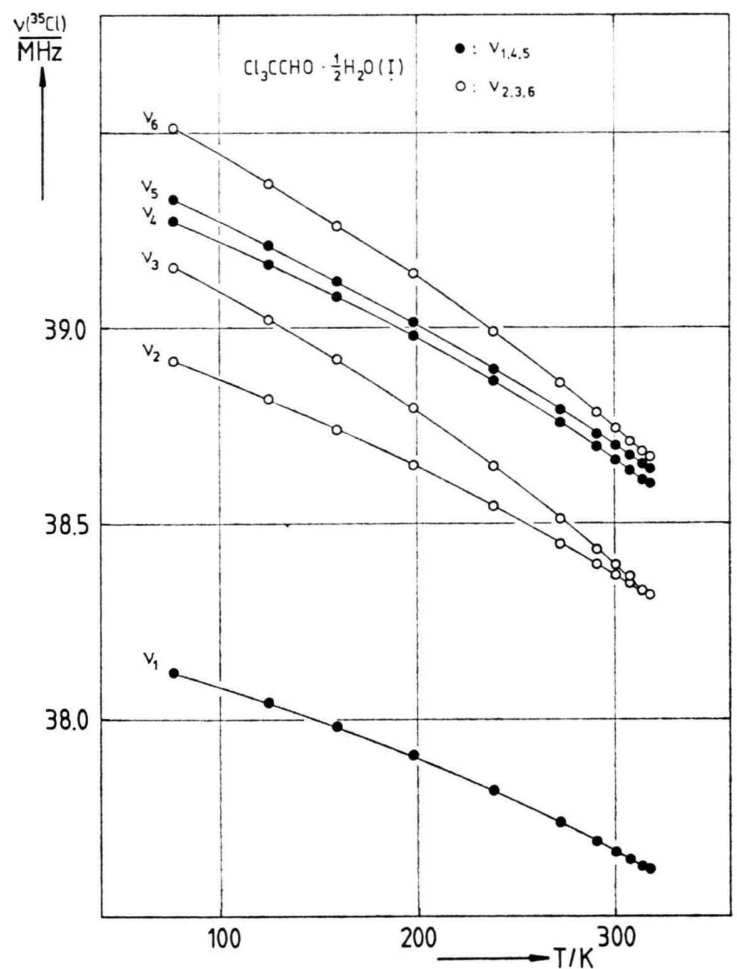

Fig. 3. Temperature dependence of the ${ }^{35} \mathrm{Cl}-\mathrm{NQR}$ frequencies in chloral hemihydrate (phase I), $\mathrm{Cl}_{3} \mathrm{CCHO} \cdot 1 / 2$ $\mathrm{H}_{2} \mathrm{O}(\mathrm{I})$.

\section{Discussion}

All compounds studied here by ${ }^{35} \mathrm{Cl}-\mathrm{NQR}$ are derivatives of chloral, $\mathrm{CCl}_{3} \mathrm{CHO}$, and by the chemical treatment of the compounds the $\mathrm{CCl}_{3}$ group was not affected. Each of the compounds shows more than three ${ }^{35} \mathrm{Cl}-\mathrm{NQR}$ lines at $77 \mathrm{~K}$, an observation which proves that more than one $\mathrm{CCl}_{3}$ group must exist within the asymmetric unit of the crystallographic unit cell. By the SEDOR technique it was possible to decide which of the ${ }^{35} \mathrm{Cl}-\mathrm{NQR}$ lines (the number $n$ of lines at $77 \mathrm{~K}$ is $5 \leqq n \leqq 12$ in the compounds studied) belongs to the same $\mathrm{CCl}_{3}$ group. The relative intramolecular assignment found in this way is shown in Table 3, together with the frequency splitting within one $\mathrm{CCl}_{3}$ group.

\section{$\alpha$ - and $\beta$-parachloral}

From ${ }^{1} \mathrm{H}$-NMR Novak and Walley [15] concluded, that $\alpha$ - and $\beta$-parachloral in chloroform solution have $\mathrm{C}_{\mathrm{s}}$ and $\mathrm{C}_{3}$ symmetry, respectively.

The molecular structure of $\alpha$-parachloral is a six membered ring having chair conformation with one 


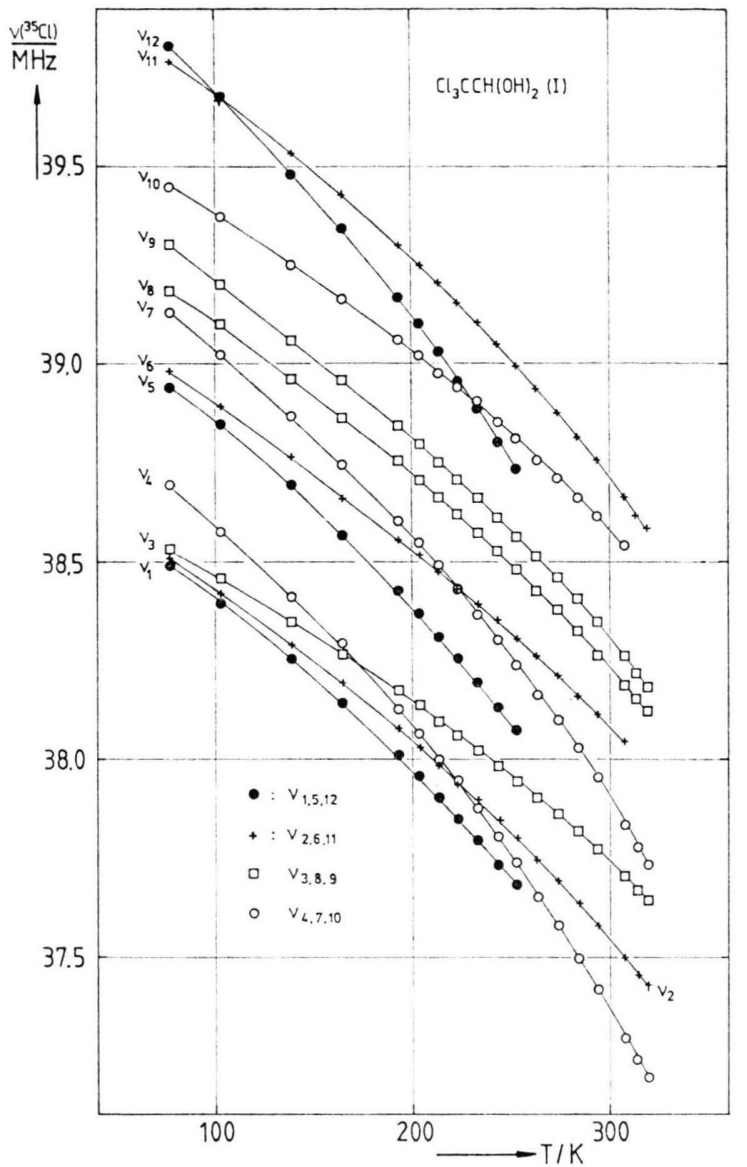

Fig. 4. Temperature dependence of the ${ }^{35} \mathrm{Cl}-\mathrm{NQR}$ frequencies in chloral hydrate (phase $\mathrm{I}), \mathrm{Cl}_{3} \mathrm{CCH}(\mathrm{OH})_{2}(\mathrm{I})$.

axial and two equatorial $\mathrm{CCl}_{3}$ groups. In Fig. 6 the structure of the molecule $\alpha$-parachloral is sketched. Thus a molecule of $\alpha$-parachloral has nine chlorine atoms, while the solid compound showed a five line ${ }^{35} \mathrm{Cl}-\mathrm{NQR}$ spectrum in the temperature range investigated. At $77 \mathrm{~K}$ four lines were observed (see Table 2 and Figure 1). This is due to an accidental coalescence of the two lines $v_{3}, v_{4}$ to an unresolved doublet at $39.755 \mathrm{MHz}$. The superposition of two lines at $77 \mathrm{~K}$ is confirmed by the $v\left({ }^{35} \mathrm{Cl}\right)=f(T)$ measurements (see Fig. 1) and by SEDOR experiments at $77 \mathrm{~K}$ and $274.8 \mathrm{~K}$.

The ${ }^{35} \mathrm{Cl}-\mathrm{NQR}$ spectrum (SEDOR) indicates that $v_{1}, v_{3}, v_{5}$ (see Table 3 and Fig. 1) belong to the two equatorial $\mathrm{CCl}_{3}$ groups and that the two equatorial $\mathrm{CCl}_{3}$ groups are crystallographically equivalent. The line group $\mathrm{b}$, which consists of two lines $\left(v_{2}\right.$ and $\left.v_{4}\right)$ is assignable to the axial $\mathrm{CCl}_{3}$ group. Two of the three chlorine atoms in the axial group

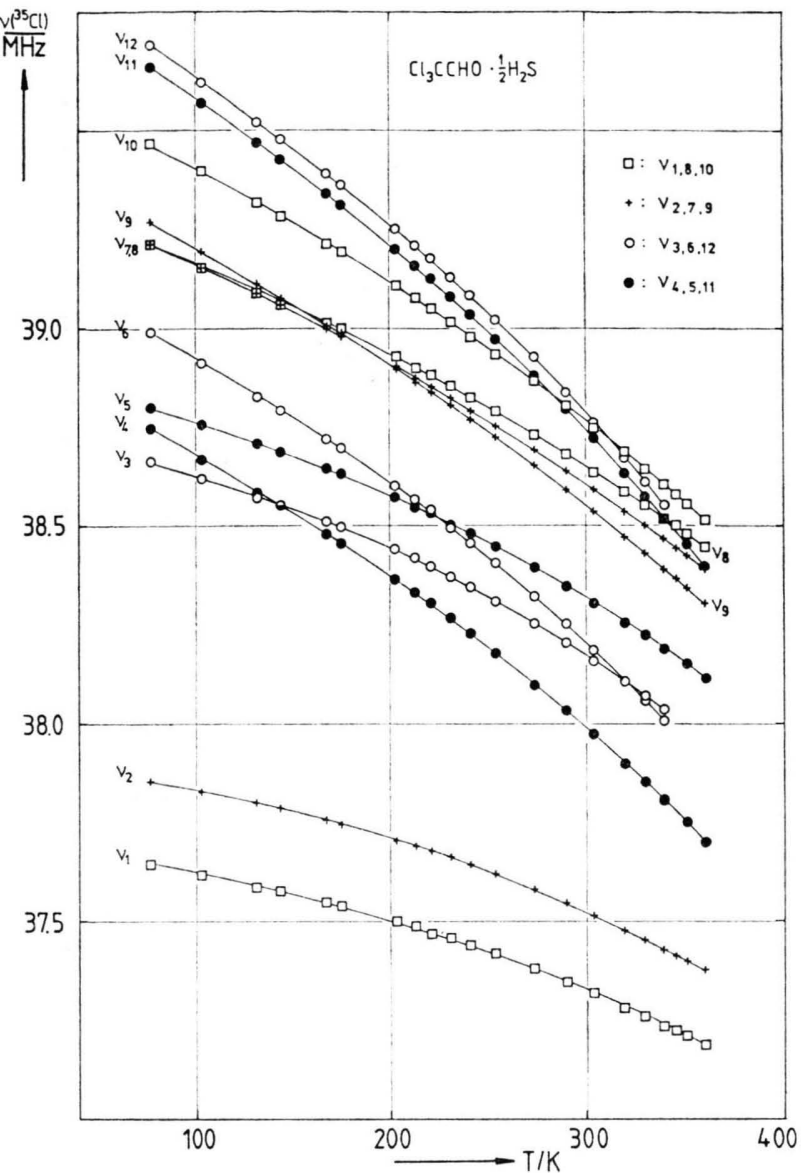

Fig. 5. Temperature dependence of the ${ }^{35} \mathrm{Cl}-\mathrm{NQR}$ frequencies in chloral hemithiohydrate, $\mathrm{Cl}_{3} \mathrm{CCHO} \cdot 1 / 2 \mathrm{H}_{2} \mathrm{~S}$.

are also equivalent. So the molecule must have $\mathrm{C}_{\mathrm{s}}$ symmetry in the crystalline state, the same symmetry as in the solution.

Since the intensity of the ${ }^{35} \mathrm{Cl}-\mathrm{NQR}$ line $v_{2}$ is two times weaker than that of $v_{4}, v_{2}$ belongs to the chlorine atom located on the symmetry plane.

On the other hand $\beta$-parachloral loses its $\mathrm{C}_{3}$ symmetry by the solid state interactions. It becomes totally asymmetric $\left(\mathrm{C}_{1}\right)$ as evidenced by the ${ }^{35} \mathrm{Cl}-\mathrm{NQR}$ spectrum:

a) Nine lines are observed and

b) SEDOR reveals three $\mathrm{CCl}_{3}$ groups, each of which is in itself asymmetric (Table 3 ).

\section{Chloral Hemihydrate}

Chloral hemihydrate, $\mathrm{Cl}_{3} \mathrm{CCHO} \cdot 1 / 2 \mathrm{H}_{2} \mathrm{O}$, appears with two crystalline phases. Nothing is known about 
Table 1. Coefficients of the power series $v\left({ }^{35} \mathrm{Cl}\right)=f(T)=A+B / T+C T+D T^{2}$. For numbering of $v$ see Table 2 .

\begin{tabular}{|c|c|c|c|c|c|c|}
\hline Compounds & $\begin{array}{l}\text { No of } \\
\text { lines }\end{array}$ & $\frac{A}{\mathrm{MHz}}$ & $\frac{B}{\mathrm{~K} \cdot \mathrm{MHz}}$ & $\frac{C \cdot 10^{3} \mathrm{~K}}{\mathrm{MHz}}$ & $\frac{D \cdot 10^{5} \mathrm{~K}^{2}}{\mathrm{MHz}}$ & $\begin{array}{l}\text { Temperature } \\
\text { range } \Delta T / \mathrm{K}\end{array}$ \\
\hline$\alpha$-parachloral & $\begin{array}{l}v_{1} \\
v_{2} \\
v_{3} \\
v_{4} \\
v_{5}\end{array}$ & $\begin{array}{l}39.1793 \\
39.6555 \\
39.7907 \\
39.7602 \\
39.8022\end{array}$ & $\begin{array}{l}8.353 \\
7.212 \\
8.904 \\
7.392 \\
6.770\end{array}$ & $\begin{array}{l}-0.7596 \\
-0.8130 \\
-1.4123 \\
-0.8685 \\
-0.6921\end{array}$ & $\begin{array}{r}-0.6783 \\
-0.5516 \\
-0.7040 \\
-0.5617 \\
-0.6058\end{array}$ & $\begin{array}{l}77-361 \\
77-361 \\
77-361 \\
77-361 \\
77-361\end{array}$ \\
\hline$\beta$-parachloral & $\begin{array}{l}v_{1} \\
v_{2} \\
v_{3} \\
v_{4} \\
v_{5} \\
v_{6} \\
v_{7} \\
v_{8} \\
v_{9}\end{array}$ & $\begin{array}{l}39.5342 \\
39.8956 \\
39.9965 \\
40.0715 \\
40.1327 \\
40.2191 \\
40.3934 \\
40.3024 \\
40.4446\end{array}$ & $\begin{array}{l}5.666 \\
4.481 \\
7.509 \\
3.579 \\
3.047 \\
3.260 \\
5.588 \\
7.110 \\
5.027\end{array}$ & $\begin{array}{l}-0.8423 \\
-2.3646 \\
-1.4269 \\
-1.5293 \\
-1.2401 \\
-1.3015 \\
-1.7907 \\
-0.6057 \\
-1.1097\end{array}$ & $\begin{array}{l}-0.5789 \\
-0.5819 \\
-0.6056 \\
-0.3112 \\
-0.3597 \\
-0.3337 \\
-0.6287 \\
-0.6486 \\
-0.5771\end{array}$ & $\begin{array}{l}77-329 \\
77-325 \\
77-329 \\
77-415 \\
77-415 \\
77-415 \\
77-329 \\
77-315 \\
77-315\end{array}$ \\
\hline $\begin{array}{l}\text { Chloralhemihydrate } \\
\text { phase I }\end{array}$ & $\begin{array}{l}v_{1} \\
v_{2} \\
v_{3} \\
v_{4} \\
v_{5} \\
v_{6}\end{array}$ & $\begin{array}{l}38.1184 \\
38.9306 \\
39.1858 \\
39.3601 \\
39.3880 \\
39.5412\end{array}$ & $\begin{array}{l}4.450 \\
5.416 \\
6.662 \\
2.132 \\
5.165 \\
6.900\end{array}$ & $\begin{array}{l}-0.3977 \\
-0.8261 \\
-1.7000 \\
-1.1861 \\
-1.3957 \\
-1.1894\end{array}$ & $\begin{array}{l}-0.3832 \\
-0.3643 \\
-0.5421 \\
-0.3813 \\
-0.3159 \\
-0.5116\end{array}$ & $\begin{array}{l}77-317 \\
77-317 \\
77-317 \\
77-317 \\
77-317 \\
77-317\end{array}$ \\
\hline Chloral hydrate phase I & $\begin{array}{l}v_{1} \\
v_{2} \\
v_{3} \\
v_{4} \\
v_{5} \\
v_{6} \\
v_{7} \\
v_{8} \\
v_{9} \\
v_{10} \\
v_{11} \\
v_{12}\end{array}$ & $\begin{array}{l}38.5016 \\
38.4560 \\
38.5185 \\
38.5797 \\
39.1385 \\
39.1221 \\
38.9697 \\
39.1676 \\
39.2105 \\
39.4191 \\
39.6395 \\
39.6887\end{array}$ & $\begin{array}{r}9.573 \\
11.299 \\
8.591 \\
15.807 \\
1.739 \\
3.981 \\
17.435 \\
10.862 \\
15.054 \\
9.564 \\
15.901 \\
18.247\end{array}$ & $\begin{array}{r}-0.9057 \\
-0.5513 \\
-0.7775 \\
-0.0550 \\
-2.1169 \\
-2.0943 \\
0.2542 \\
-1.0042 \\
-0.6569 \\
-0.6093 \\
-0.1581 \\
-0.4354\end{array}$ & $\begin{array}{l}-0.9798 \\
-0.8779 \\
-0.6403 \\
-1.3968 \\
-0.8391 \\
-0.4770 \\
-1.3490 \\
-0.7471 \\
-0.8472 \\
-0.7696 \\
-1.0416 \\
-1.4364\end{array}$ & $\begin{array}{l}77-253 \\
77-318 \\
77-318 \\
77-318 \\
77-253 \\
77-306 \\
77-318 \\
77-318 \\
77-318 \\
77-306 \\
77-318 \\
77-253\end{array}$ \\
\hline Chloral hemithiohydrate & $\begin{array}{l}v_{1} \\
v_{2} \\
v_{3} \\
v_{4} \\
v_{5} \\
v_{6} \\
v_{7} \\
v_{8} \\
v_{9} \\
v_{10} \\
v_{11} \\
v_{12}\end{array}$ & $\begin{array}{l}37.6172 \\
37.8540 \\
38.5769 \\
38.7532 \\
38.7529 \\
38.9472 \\
39.3068 \\
39.2323 \\
39.2897 \\
39.5554 \\
39.6434 \\
39.6424\end{array}$ & $\begin{array}{r}3.439 \\
2.021 \\
7.512 \\
7.586 \\
6.229 \\
10.062 \\
2.936 \\
5.935 \\
8.065 \\
4.290 \\
10.494 \\
13.171\end{array}$ & $\begin{array}{r}0.0551 \\
-0.0411 \\
0.3060 \\
-0.9707 \\
-0.0681 \\
-0.6307 \\
-1.4155 \\
-0.9180 \\
-1.2689 \\
-1.5571 \\
-1.0267 \\
-0.6677\end{array}$ & $\begin{array}{l}-0.3546 \\
-0.3592 \\
-0.5801 \\
-0.5536 \\
-0.4837 \\
-0.6523 \\
-0.3167 \\
-0.3620 \\
-0.4235 \\
-0.3761 \\
-0.6985 \\
-0.7816\end{array}$ & $\begin{array}{l}77-361 \\
77-361 \\
77-340 \\
77-361 \\
77-361 \\
77-340 \\
77-361 \\
77-361 \\
77-361 \\
77-361 \\
77-361 \\
77-340\end{array}$ \\
\hline
\end{tabular}

their crystal structure; also the relations between $\mathrm{Cl}_{3} \mathrm{CCHO} \cdot 1 / 2 \mathrm{H}_{2} \mathrm{O}$ (I) and $\mathrm{Cl}_{3} \mathrm{CCHO} \cdot 1 / 2 \mathrm{H}_{2} \mathrm{O}$ (II) are not clear yet. From the crystallographic point of view the six ${ }^{35} \mathrm{Cl}-\mathrm{NQR}$ lines of chloral hemihydrate (I) can be accounted for by one of the two following models: the unit cell contains (1) one molecule in the asymmetric unit with two crystallographically inequivalent $\mathrm{CCl}_{3}$ groups or (2) two molecules in the asymmetric unit, each having $\mathrm{C}_{\mathrm{s}}\left(\right.$ or $\mathrm{C}_{2}$ ) sym- metry ${ }^{*}$. Both models are in accordance with SEDOR experiments and no decision between (1) and (2) is possible on the basis of ${ }^{35} \mathrm{Cl}-\mathrm{NQR}$. Model (1) seems to be the more likely one in accordance with an ether bridged molecular structure. In Fig. 7 the

* If the molecule maintains the $\mathrm{C}_{3}$ symmetry in the crystalline state, there must be three independent molecules in the unit cell, to account for a nine line NQP spectrum. This is, however, crystallographically difficult. 
Table 2. The ${ }^{35} \mathrm{Cl}-\mathrm{NQR}$ frequencies, $v\left({ }^{35} \mathrm{Cl}\right)$, at $77 \mathrm{~K}$, signal to noise ratios ${ }^{a}, S / N$, fade out temperatures, $T_{\mathrm{f}}$, and melting points, $T_{\mathrm{m}}$, of some chloral derivatives.

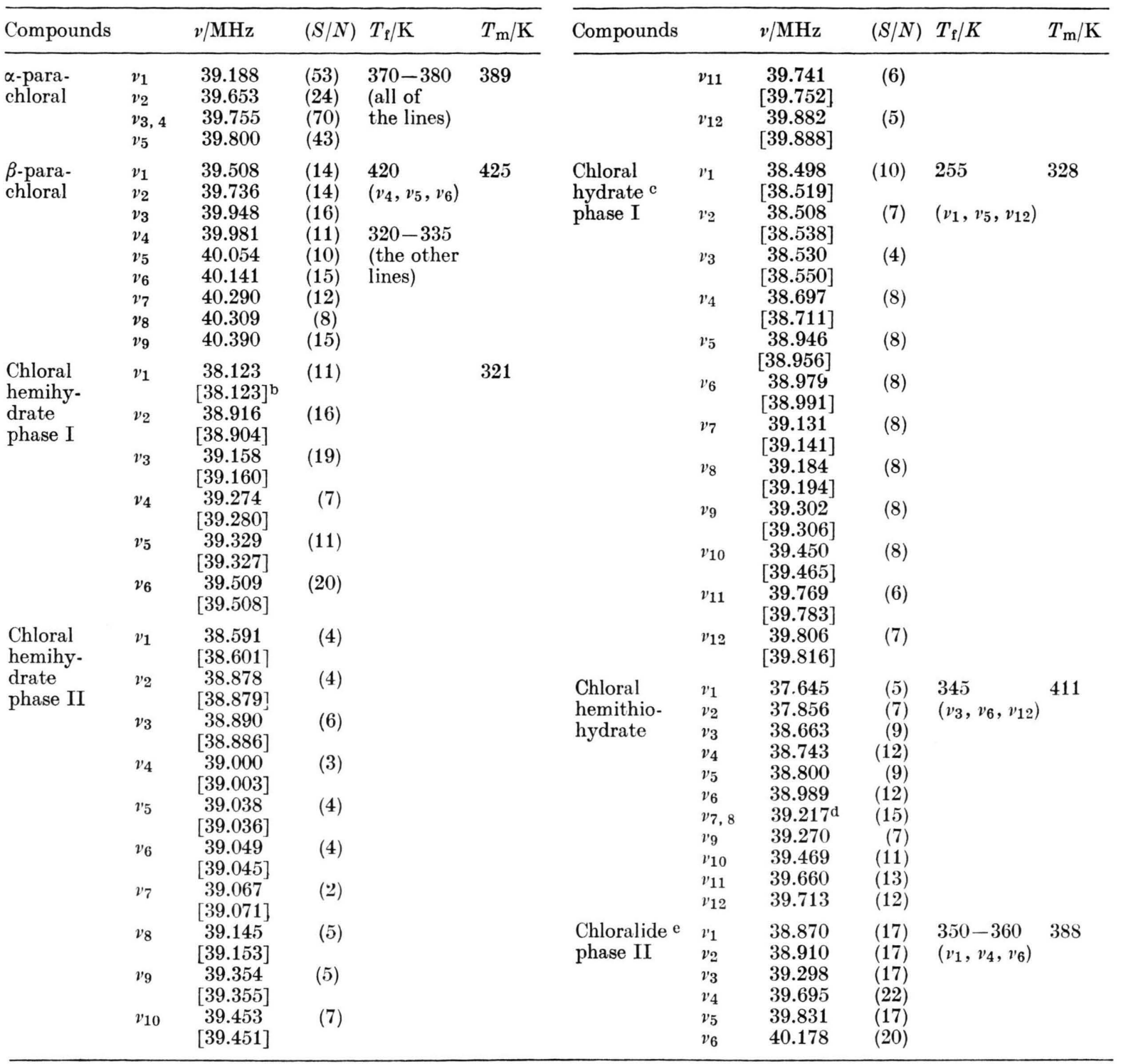

a $S / N$ measured with lock in technique and a time constant $\tau=10 \mathrm{sec}$.

b The frequencies in the paranthese, [ ], correspond to the deuterate.

NQR line groups are shown in form of a stick diagram. Twelve ${ }^{35} \mathrm{Cl}-\mathrm{NQR}$ lines are found for $\mathrm{Cl}_{3} \mathrm{CCHO} \cdot 1 / 2 \mathrm{H}_{2} \mathrm{O}$ (II). A comparison of the assignment of the frequencies to different $\mathrm{CCl}_{3}$ groups in phase I and phase II leads to the assumption that the line group a in phase I corresponds to the groups $a$ and $a^{\prime}$ in phase II and group $b$ to $b$ and c The data were taken from ref. [3].

d The superposition of two lines was confirmed by the frequency vs. temperature relationships.

e This compound has a phase transition at $344 \mathrm{~K}$ (Ref. [6])

$\mathbf{b}^{\prime}$. This proposal is based on (1) the large frequency splitting of line group a in phase I and II; and (2) the fact that both groups b show nearly the same frequencies in phase I and phase II. Thus on the basis of the SEDOR experiments one can suggest that the twelve NQR-lines belong to two crystallographically nonequivalent molecules. 
Table 3. Line groups as determined by SEDOR and frequency splittings, $\Delta v$, of each line group at $T=77 \mathrm{~K}$.

\begin{tabular}{|c|c|c|c|}
\hline Compounds & $\begin{array}{l}\text { Line } \\
\text { Group }\end{array}$ & Components & $\Delta v / \mathrm{MHz}$ \\
\hline$\alpha$-parachloral * & $\begin{array}{l}\mathrm{a} \\
\mathrm{b}\end{array}$ & $\begin{array}{l}v_{1}, v_{2}, v_{5} \\
v_{2}, v_{4}\end{array}$ & $\begin{array}{l}0.61 \\
0.10\end{array}$ \\
\hline$\beta$-parachloral & $\begin{array}{l}\mathrm{a} \\
\mathrm{b} \\
\mathrm{c}\end{array}$ & $\begin{array}{l}v_{1}, v_{7}, v_{8} \\
v_{2}, v_{3}, v_{9} \\
v_{4}, v_{5}, v_{6}\end{array}$ & $\begin{array}{l}0.80 \\
0.65 \\
0.16\end{array}$ \\
\hline $\begin{array}{l}\text { Chloral hemihydrate } \\
\text { phase I }\end{array}$ & $\begin{array}{l}\mathrm{a} \\
\mathrm{b}\end{array}$ & $\begin{array}{l}v_{1}, v_{4}, v_{5} \\
v_{2}, v_{3}, v_{6}\end{array}$ & $\begin{array}{l}1.21 \\
0.59\end{array}$ \\
\hline $\begin{array}{l}\text { Chloral hemihydrate } \\
\text { phase II }\end{array}$ & $\begin{array}{l}\mathrm{a} \\
\mathrm{a}^{\prime} \\
\mathrm{b} \\
\mathrm{b}^{\prime}\end{array}$ & $\begin{array}{l}v_{1}, v_{9}, v_{12} \\
v_{3}, v_{5}, v_{11} \\
v_{2}, v_{8}, v_{10} \\
v_{4}, v_{6}, v_{7}\end{array}$ & $\begin{array}{l}1.29 \\
0.85 \\
0.58 \\
0.07\end{array}$ \\
\hline $\begin{array}{l}\text { Chloral hydrate } \\
\text { phase I }\end{array}$ & $\begin{array}{l}\mathrm{a} \\
\mathrm{a}^{\prime} \\
\mathrm{b} \\
\mathrm{b}^{\prime}\end{array}$ & $\begin{array}{l}v_{1}, v_{5}, v_{12} \\
v_{2}, v_{6}, v_{11} \\
v_{3}, v_{8}, v_{9} \\
v_{4}, v_{7}, v_{10}\end{array}$ & $\begin{array}{l}1.31 \\
1.26 \\
0.77 \\
0.75\end{array}$ \\
\hline $\begin{array}{l}\text { Chloralide } \\
\text { phase II }\end{array}$ & $\begin{array}{l}\mathrm{a} \\
\mathrm{b}\end{array}$ & $\begin{array}{l}v_{1}, v_{4}, v_{6} \\
v_{2}, v_{3}, v_{5}\end{array}$ & $\begin{array}{l}1.31 \\
0.92\end{array}$ \\
\hline $\begin{array}{l}\text { Chloral } \\
\text { hemithiohydrate }\end{array}$ & $\begin{array}{l}\mathrm{a} \\
\mathrm{a}^{\prime} \\
\mathrm{b} \\
\mathrm{b}^{\prime}\end{array}$ & $\begin{array}{l}v_{1}, v_{8}, v_{10} \\
v_{2}, v_{7}, v_{9} \\
v_{3}, v_{6}, v_{12} \\
v_{4}, v_{5}, v_{11}\end{array}$ & $\begin{array}{l}1.82 \\
1.41 \\
1.05 \\
0.92\end{array}$ \\
\hline
\end{tabular}

* Complete assignment by SEDOR has been carried out at $T=274.8 \mathrm{~K}$. For the other compounds the assignment to the different line groups was done by SEDOR technique at $77 \mathrm{~K}$.

\section{Chloral Hydrate (I)}

SEDOR divides the twelve ${ }^{35} \mathrm{Cl}-\mathrm{NQR}$ lines of chloralhydrate (phase I) into four line groups, which correspond to four crystallographically inequivalent $\mathrm{CCl}_{3}$ groups. Therefore the unit cell of this solid must contain four molecules within the asymmetric unit. In Fig. 7 the spectrum divided up into the different groups is shown. It is noted that the splitting pattern of the line groups $a$ and $a^{\prime}$ (and $b$ and $b^{\prime}$ also) are strikingly similar to each other. Although four nonequivalent molecules in the solid evidently

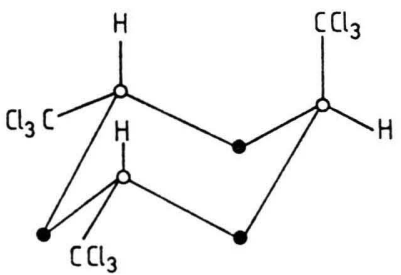

$$
0:[, \bullet: 0
$$

Fig. 6. Structure of the molecule $\alpha$-parachloral, $\alpha$ $\left(\mathrm{Cl}_{3} \mathrm{CCHO}\right)_{3}$.

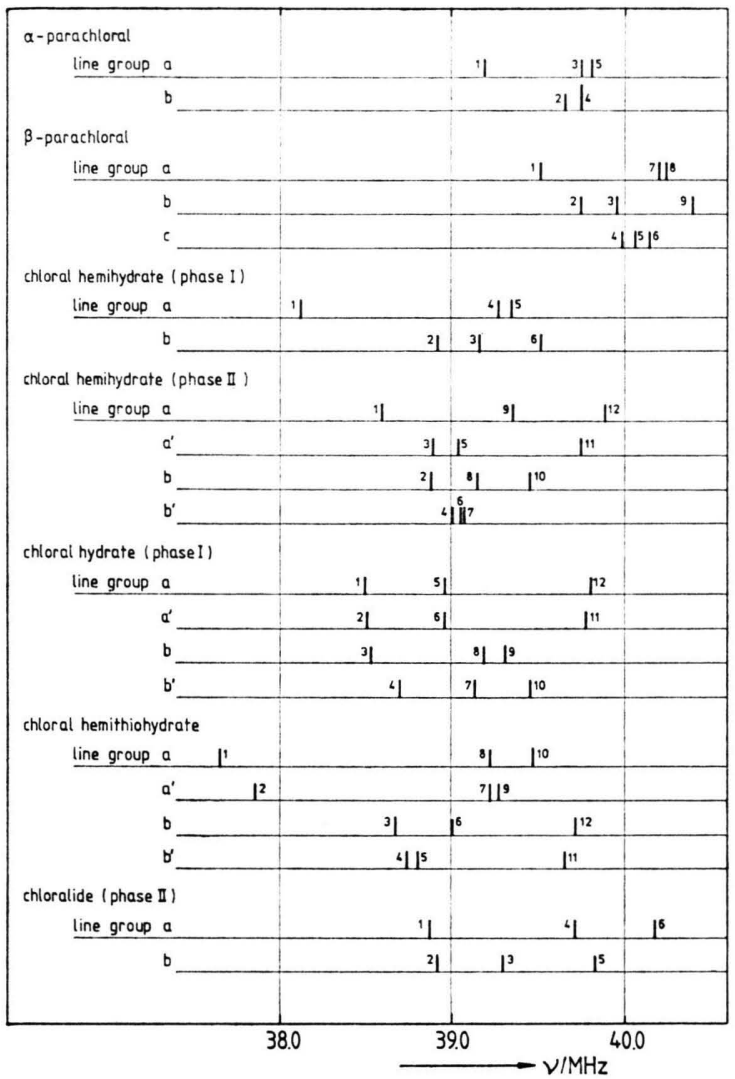

Fig. 7. Stick diagram of the ${ }^{35} \mathrm{Cl}-\mathrm{NQR}$ frequencies in several derivates of chloral, $\mathrm{CCl}_{3} \mathrm{CHO}$.

exist as mentioned above, there seems to be a pseudosymmetry which makes the molecules pairwise almost equivalent.

\section{Chloralhemithiohydrate}

Chloralhemithiohydrate is assumed to have a thioether structure [10]:<smiles>OC(SC(O)C(Cl)(Cl)Cl)C(Cl)(Cl)Cl</smiles>

Based on SEDOR, the twelve ${ }^{35} \mathrm{Cl}-\mathrm{NQR}$ lines of chloralhemithiohydrate are divided into four line groups shown in Table 3 and Figure 7. The splitting pattern of line group a bears a striking resemblance to that of line group $a^{\prime}$. Similarly the splitting patterns of line group $b$ and $b^{\prime}$ are quite alike. These facts suggest that line-group $a$ and $b$ belong to one crystallographically independent molecule and the 
line group $\mathrm{a}^{\prime}$ and $\mathrm{b}^{\prime}$ to another molecule. It is interesting to compare the NQR spectra of chloralhemithiohydrate and chloralhemihydrate. The two molecules have a common structure, the former being a thioether and the latter an ether. From this structural similarity one may expect a resemblance between their NQR spectra. In fact the two compounds show quite similar NQR spectra (see Figure 7). It is obvious that the line groups a and $\mathrm{a}^{\prime}$ of the hemithiohydrate correspond to the line groups $\alpha$ of chloralhemihydrate (I) and chloralhemihydrate (II). These four line groups are characterized by their large frequency splittings. Since this feature is common to the two compounds, the large frequency splitting is attributable to an intramolecular origin. Moreover, it will possibly be of steric nature, because the hemithiohydrate shows much larger splittings.

\section{Frequency Splitting}

The magnitude of the frequency splittings of $\alpha$ and $\beta$-parachloral $\left((\Delta v)_{a}=0.61 \mathrm{MHz}, \quad(\Delta v)_{\beta}=\right.$ $0.88 \mathrm{MHz}$ at $77 \mathrm{~K}$ ) is of the order of the crystal field splitting observed for ${ }^{35} \mathrm{Cl}-\mathrm{NQR}$ on chlorine bonded to carbon [16]. In the line group a of chloralhemihydrate (I) the frequency $v_{1}$ is strongly depressed compared to the other lines, whereby a large frequency splitting of $\Delta v=1.21 \mathrm{MHz}$ results for this group. For sine group a in chloralhemihydrate(II) $\Delta v=1.29 \mathrm{MHz}$ has been obtained (Table 3 ). Line groups a and a' of chloralhydrate(I) exhibit splittings of similar magnitude $(\Delta v=$ $1.31 \mathrm{MHz}$ and $1.26 \mathrm{MHz}$, respectively). Among the compounds studied here, chloralhemithiohydrate shows the largest splitting of almost $2 \mathrm{MHz}$ (group a). The magnitude of these splittings is too large to be explained simply by crystal field effects, because for $\mathrm{CCl}_{3}$ groups they do not exceed $1 \mathrm{MHz}$ [5]. It is tempting to assume $\mathrm{Cl}$... H type hydrogen bond formation in crystallized chloralhydrate(I) and chloralhemihydrate (I). However, this assumption should be excluded, at least for $\mathrm{Cl}_{3} \mathrm{CCH}(\mathrm{OH})_{2}(\mathrm{I})$ and $\mathrm{Cl}_{3} \mathrm{CCHO} \cdot 1 / 2 \mathrm{H}_{2} \mathrm{O}(\mathrm{I})$ because no significant change in $v\left({ }^{35} \mathrm{Cl}\right)$ was originated by deuteration, as shown in Table 1. For chloralhydrate(II) it has been shown

[1] J. Liebig, Ann. Pharmazia, 1, 182 (1932).

[2] F. I. Luknitskii, Chem. Rev. 75, 259 (1975).

[3] D. Biedenkapp and A. Weiss, Z. Naturforsch. 22a, 1124 (1967). by deuteration experiments that the frequency splitting $\Delta v=1.43 \mathrm{MHz}$ at $77 \mathrm{~K}$ is not due to hydrogen bonds $\mathrm{Cl} \ldots \mathrm{H}[3,17]$.

The origin responsible for the large $\Delta v$ 's, in the compounds considered here is most probably intramolecular. In this connection it is interesting to note that the largest splitting observed was for $\mathrm{Cl}_{3} \mathrm{CCHO} \cdot 1 / 2 \mathrm{H}_{2} \mathrm{~S}$, a compound in which one of the neighbours of the $\mathrm{CCl}_{3}$ group is the bulky sulfur atom.

\section{Fade Out}

It is well known that the Cl-NQR signals of $\mathrm{CCl}_{3}$ groups often fade out at temperatures far below the melting point. This phenomenon has been ascribed to the occurance of reorientational motions of the group around its three fold axis [18]. In general $T_{\mathrm{f}}$ tends to rise with increasing magnitude of the potential barrier which hinders the reorientational motion [19-22]. For the compounds studied here, most of the $T_{\mathrm{f}}$ are higher than $320 \mathrm{~K}$, except for the line group a of $\mathrm{Cl}_{3} \mathrm{CCH}(\mathrm{OH})_{2}(\mathrm{I}) . T_{\mathrm{f}, \max }=420 \mathrm{~K}$ was found for chloralide (II), line group a. These values are much higher than those found for $\mathrm{CCl}_{3}$ groups in trichloroacetates [5]. In both cases a $\mathrm{CCl}_{3}$ group has the configuration $\mathrm{COO}$ as neighbours, but the electronic configurations of the carbon attached to $\mathrm{Cl}_{3} \mathrm{C}$ differ from each other. It is $\mathrm{sp}^{3}$ (chloral derivatives) and $\mathrm{sp}^{2}$ (trichloroacetates), respectively. Thus it can be seen that the reorientational motion of $\mathrm{CCl}_{3}$ groups attached to $\mathrm{C}\left(\mathrm{sp}^{3}\right)$ is much more hindered by a potential barrier higher than that of $\mathrm{Cl}_{3} \mathrm{C}-\mathrm{C}\left(\mathrm{sp}^{2}\right)$.

One of the three $\mathrm{CCl}_{3}$ groups of $\beta$-parachloral differs in $T_{\mathrm{f}}$ considerably from the two other groups. This difference is induced by intermolecular forces because in solution the three $\mathrm{CCl}_{3}$ groups are equivalent. A detailed discussion on this point, however, rests on the knowledge of the crystal structure.

\section{Acknowledgement}

We are grateful to the Deutsche Forschungsgemeinschaft and the Fonds der Chemischen Industrie for support of this work. M. Hashimoto is obliged to the Alexander v. Humboldt-Stiftung for a fellowship.

[4] M. Hashimoto and A. Weiss, J. Mol. Struct. 58, 243 (1980).

[5] M. Hashimoto, M. Watanabe, and H. Takada, J. Magn. Reson. 34, 553 (1979). 
[6] M. Hashimoto, H. Paulus, and A. Weiss, Ber. Bunsenges., Physik. Chem., 84, 883 (1980).

[7] M. Emshwiller, E. L. Hahn, and D. Kaplan, Phys. Rev. 118, 414 (1960).

[8] N. Weiden and A. Weiss, J. Magn. Reson. 30, 403 (1978).

[9] N. Weiden and A. Weiss, Faraday Disc. Chem. Soc. Faraday Sympos. 13, 93 (1979).

[10] F. D. Chattaway and E. G. Kellett, J. Chem. Soc. 1929, 2908.

[11] F. D. Chattaway and E. G. Kellett, J. Chem. Soc. 1928, 2709.

[12] C. van Rossen, Z. Phys. Chem. 62, 681 (1908).

[13] G. Shill, Svensk. Farm. Tid. 53, 165 (1949).

[14] H. Bayer, Z. Physik 130, 227 (1951).
[15] A. Novak and E. Whalley, Can. J. Chem. 36, 1116 (1958).

[16] A. Weiss, Topics Current Chem. 30, 1 (1972).

[17] H. Chihara and N. Nakamura, Bull. Chem. Soc. Japan 45, 3530 (1972).

[18] M. Buyle-Bodin, Ann. Phys. Paris 10, 533 (1955).

[19] I. V. Izmest'ev and V. S. Grechishkin, Zh. Strukt. Khim. 11, 927 (1970).

[20] N. E. Ainbinder, B. F. Amivkhanov, I. V. Izmest'ev, A. N. Osipenko, and G. B. Soifer, Sov. Physics-Solid State 13, 344 (1971).

[21] T. Kiichi, N. Nakamura, and H. Chihara, J. Magn. Reson. 6, 516 (1972).

[22] H. Chihara and N. Nakamura, Bull. Chem. Soc. Japan 45, 3530 (1972). 